\title{
Integrative Gene Cloning and Expression System for Streptomyces sp. US 24 and Streptomyces sp. TN 58 Bioactive Molecule Producing Strains
}

\author{
Samiha Sioud, ${ }^{1}$ Bertrand Aigle, ${ }^{2}$ Ines Karray-Rebai, ${ }^{1}$ Slim Smaoui, ${ }^{1}$ \\ Samir Bejar, ${ }^{1}$ and Lotfi Mellouli ${ }^{1}$ \\ ${ }^{1}$ Laboratory of Prokaryotic Enzymes and Metabolites, Centre of Biotechnology of Sfax, Road of Sidi Mansour Km 6, \\ P. O. Box 1177, 3018 Sfax, Tunisia \\ ${ }^{2}$ Laboratory of Genetic and Microbiology, UMR INRA 1128, IFR 110, Faculty of Sciences and Techniques, \\ University Henri Poincaré, Vandoeuvre-lès-Nancy, 54003 Nancy Cedex, France
}

Correspondence should be addressed to Lotfi Mellouli, lotfi.mallouli@cbs.rnrt.tn

Received 2 December 2008; Accepted 26 March 2009

Recommended by Isaac K. O. Cann

Streptomyces sp. US 24 and Streptomyces sp. TN 58, two strains producing interesting bioactive molecules, were successfully transformed using E. coli ET12567 (pUZ8002), as a conjugal donor, carrying the integrative plasmid pSET152. For the Streptomyces sp. US 24 strain, two copies of this plasmid were tandemly integrated in the chromosome, whereas for Streptomyces sp. TN 58 , the integration was in single copy at the attB site. Plasmid pSET152 was inherited every time for all analysed Streptomyces sp. US 24 and Streptomyces sp. TN 58 exconjugants under nonselective conditions. The growth, morphological differentiation, and active molecules production of all studied pSET152 integrated exconjugants were identical to those of wild type strains. Consequently, conjugal transfer using pSET152 integration system is a suitable means of genes transfer and expression for both studied strains. To validate the above gene transfer system, the glucose isomerase gene (xylA) from Streptomyces sp. SK was expressed in strain Streptomyces sp. TN 58. Obtained results indicated that heterologous glucose isomerase could be expressed and folded effectively. Glucose isomerase activity of the constructed TN 58 recombinant strain is of about eighteenfold higher than that of the Streptomyces sp. SK strain. Such results are certainly of importance due to the potential use of improved strains in biotechnological process for the production of high-fructose syrup from starch.

Copyright () 2009 Samiha Sioud et al. This is an open access article distributed under the Creative Commons Attribution License, which permits unrestricted use, distribution, and reproduction in any medium, provided the original work is properly cited.

\section{Introduction}

At the end of the last century, in addition to the conventional screening of naturally occurring bioactive compounds, a strategy was developed to construct desired novel hybrid antibiotics by combinatorial biosynthesis, by specifically combining genes from various biosynthetic pathways originating from different antibiotics producing organisms. In Streptomyces species, the most important producers of bioactive molecules, genetic approaches to improve secondary metabolite production are generally hampered by various phenomena such as restriction barriers, absence of an efficient gene transfer systems, and lack of suitable cloning vectors. Recently, in order to circumvent these problems, there has been considerable interest in the use of intergeneric conjugation as an efficient means of gene transfer and expression in Streptomyces species. This technique allows the construction and the manipulation of recombinant plasmids in E. coli and their subsequent transfer to a recipient of interest. The initial protocol for intergeneric transfer of plasmids from E. coli to Streptomyces species was developed by Mazodier et al. [1]. Since then, this method has been successfully applied to several Streptomyces species [24] via methylation-deficient E. coli strains, such as strain ET12567 [5], as a DNA donor to avoid methylated DNA restriction systems of actinomycetes [6]. Several cloning vectors that could be transferred from E. coli to Streptomyces species by conjugation method have been constructed [7, 8]. Among them, pSET152 is a nonreplicative plasmid in Streptomyces that carries the attP site and integrase 
gene of $\varphi \mathrm{C} 31$ phage and consequently can integrate into the chromosomal attB site of the bacteriophage $\varphi \mathrm{C} 31$. Like $\lambda$ integrases, $\varphi \mathrm{C} 31$ integrase catalyses the site-specific recombination between the chromosomal attB site and an $a t t P$ site to form attL and attR. However, unlike those of $\lambda$ integrases, the sites are both very small, with attP and attB being just 39 and $34 \mathrm{pb}$ in size, respectively [9]. The DNA sequences of attB were characterized from various Streptomyces species, and the analysis of these sequences revealed the presence of high conserved positions. In this genus of bacteria, the presence of pseudo-attB sites (50\% $70.3 \%$ nt identity to attB sites) has also been reported, but with an integration frequency 300 times lower than that with the corresponding attB site [10]. However, the absence of this attB site from some actinomycete strains, such as Saccharopolyspora erythraea, has also been reported [11].

We have previously reported the isolation from Tunisian soil of two new actinomycete strains called Streptomyces sp. US 24 [12] and Streptomyces sp. TN 58 [13], producing diverse interesting biological activities, and described the purification and structure elucidation of two and five active molecules from the Streptomyces sp. US 24 [14] and the Streptomyces sp. TN 58 [15], respectively. The active molecules produced by Streptomyces sp. US 24 are the 3 -indolethanol and a diketopiperazine (DKP) derivative, the Cyclo (L-Phe, L-Pro) diketopiperazine. DKP active molecules form a very important family because of their many potential uses as antibacterial, fungicidal, herbicidal, antiviral, immune-suppressor, and antitumor agents, and therefore they are very attractive for the production of novel hybrid active compounds by combinatorial biosynthesis.

Among the five active molecules characterised from the Streptomyces sp. TN 58, two belong to the rhamnopyranoside family: the 1-O-(2-Aminobenzoyl)- $\alpha$-L-rhamnoside and the 4-Hydroxybenzoyl $\alpha$-L-rhamnopyranoside. These two active compounds possess inhibitory activity towards $3 \alpha$-hydroxysteroid dehydrogenase ( $3 \alpha-\mathrm{HSD})$, a useful target for anti-inflammatory and antiphlogistic drugs. It should be noted that until now, the Streptomyces sp. TN 58 is the only described strain which produces these two molecules directly without any supplement addition into the culture media [15]. Identification and expression of genes involved in biosynthetic pathways of these molecules constitute a real opportunity for the comprehension of their natural biosynthesis and subsequently the production of hybrid molecules. The aim of this work was thus to succeed in carrying out intergeneric conjugation between E. coli ET12567 and Streptomyces sp. US 24 and TN 58 strains, to analyse the integration sites of the integrative vector pSET152 into the chromosome of these two Streptomyces strains, to study whether the site-specific integration of pSET152 affects essential functions such as the production of active molecules in these two studied strains, and to verify the expression of a heterologous gene in Streptomyces sp. TN 58 strain using this system.

\section{Materials and Methods}

2.1. Bacterial Strains and Plasmids. E.coli strain ET12567 (pUZ8002) [2,5], used as the donor in intergeneric conjugation, is a methylation-defective strain (dam-13:: Tn9 dcm-6 hsdM Cmr). E. coli strain DH5 $\alpha$ [16] ( $\mathrm{F}^{-} \phi 80 \mathrm{~d} l a c Z \triangle \mathrm{M} 15$ $\Delta($ lacZYA-argF $)$ U169 endA1 recA1hsdR17 $\left(\mathrm{r}^{-}{ }_{\mathrm{k}}, \mathrm{m}^{+}{ }_{\mathrm{k}}\right)$ deoR thi-1 susE44 $\lambda^{-}$gyrA96 relA1) and E. coli HB101 $\left(F^{-}\right.$hsdS2 recA13 ara $^{-} 14$ pro A2 lacY1 galk2 rps L20 $x y l^{-} 5$ mtl sup E44) were used as host strain, and E. coli ATCC 8739 and Micrococcus luteus LB 14110 were used as indicator microorganisms for the antibacterial activity assays.

The two Streptomyces strains US 24 [12] and TN 58 [13] were used as recipient for intergeneric conjugation. Streptomyces SK strain is a thermostable glucose isomerase producer [17]. CBS4 strain was the glucose isomerase deficient Streptomyces violaceoniger in which the xylA gene of the Streptomyces SK strain, under the control of the ermEup constitutive promoter, was integrated in its chromosome via the integrative vector pTS55 [18].

Plasmid pUZ8002 is a derivative of RK2 with a mutation in oriT [19]. pSET152 is an integrative plasmid carrying $\varphi \mathrm{C} 31$ int and att functions and an apramycin resistance gene for selection in Streptomyces and E. coli [2]. pGEM-T Easy vector is a TA cloning vector $\mathrm{Amp}^{\mathrm{R}}$ (Promega) used for cloning of the PCR products.

2.2. Media and Culture Conditions. E. coli strains were grown in Luria broth (LB) medium. Ampicillin $\left(50 \mu \mathrm{g} \mathrm{mL}^{-1}\right)$, chloramphenicol $\left(25 \mu \mathrm{g} \mathrm{mL}^{-1}\right)$, nalidixic acid, and kanamycin $\left(50 \mu \mathrm{g} \mathrm{mL}^{-1}\right)$ were added to growth media when required and 5-bromo-4-chloro-3-indolyl- $\beta$-D-galacto pyranoside $\left(40 \mu \mathrm{g} \mathrm{mL}^{-1}\right)$ when appropriate [20]. Transfor mation of E. coli DH5 $\alpha$ or HB101 with pGEM-T pSET152 derivatives was carried out according to the manufacturer's instructions (Promega).

Streptomyces sp. US 24 and TN 58 strains were grown in Tryptone soya broth (TSB: $30 \mathrm{~g}$ tryptic soy broth plus $5 \mathrm{~g}$ yeast extract per $1000 \mathrm{~mL}$ distilled water) medium for the preparation of genomic DNA [21] and in R2YE [22] plates for the preparation of spore stocks. TSB supplemented with $30 \mu \mathrm{g}$ of apramycin $\mathrm{mL}^{-1}$ was used to grow exconjugants for the preparation of genomic DNA and to maintain them.

AS1 medium [23] (1 gYeast extract, $5 \mathrm{~g}$ Soluble starch, $0.2 \mathrm{~g}$ L-alanine, $0.2 \mathrm{~g}$ L-arginine, $0.5 \mathrm{~g}$ L-asparagine, $2.5 \mathrm{~g}$ $\mathrm{NaCl}, 10 \mathrm{~g} \mathrm{Na} 2 \mathrm{SO}_{4}$ and $20 \mathrm{~g}$ agar, $\mathrm{pH}$ adjusted at 7.5 with $\mathrm{KOH})$ was used for conjugation experiments.

For bioactive molecules production, Streptomyces sp. US 24 strain and the corresponding exconjugants were grown in TSB medium, supplemented at $1 \%(\mathrm{w} / \mathrm{v})$ with starch and with a trace element solution: $\left(7.5 \mathrm{mLL}^{-1}\right.$ final; $0.4 \mathrm{gL}^{-1} \quad \mathrm{ZnCl}_{2} ; 2 \mathrm{~g} \mathrm{~L}^{-1} \quad \mathrm{FeSO}_{4} \cdot 7 \mathrm{H}_{2} \mathrm{O} ; 0.065 \mathrm{~g} \mathrm{~L}^{-1} \quad \mathrm{H}_{3} \mathrm{BO}_{3}$ and $\left.0.135 \mathrm{~g} \mathrm{~L}^{-1} \quad \mathrm{MoNa}_{2} \mathrm{O}_{4} \cdot 2 \mathrm{H}_{2} \mathrm{O}\right)$. Streptomyces $\mathrm{TN} 58$ strain and corresponding exconjugants were grown in TSB medium, supplemented with glycerol at $1 \%(\mathrm{w} / \mathrm{v})$ and with potassium at $1 \mathrm{mmol} \mathrm{L}^{-1}$. For antibacterial activity determination, indicator microorganisms were grown overnight in $\mathrm{LB}$ medium at $30^{\circ} \mathrm{C}$ for M. luteus LB14110 and at $37^{\circ} \mathrm{C}$ for E. coli ATCC 8739, then diluted $1: 100$ in LB medium and 
incubated for 5 hours under constant agitation at $200 \mathrm{rpm}$ at the appropriate temperature.

For growth study of the two bacteria: Streptomyces TN 58/xylA and CBS4, spores at $10^{7} \mathrm{~mL}^{-1}$ of each strain were used to inoculate $1000 \mathrm{~mL}$ Erlenmeyer flasks with four indents, containing $200 \mathrm{~mL}$ of minimum liquid medium ( $\left[\mathrm{NH}_{4}\right]_{2} \mathrm{SO}_{4} 2.5 \mathrm{~g} \mathrm{~L}^{-1}, \mathrm{MgSO}_{4} 0.3 \mathrm{gL}^{-1}, \mathrm{CaCl}_{2} 0.2 \mathrm{gL}^{-1}$, $\mathrm{KH}_{2} \mathrm{PO}_{4} 1 \mathrm{~g} \mathrm{~L}^{-1}$, yeast extract $1 \mathrm{~g} \mathrm{~L}^{-1}$ and $1 \mathrm{~mL}$ of trace element solution) in presence of xylose as solely carbon source at $10 \mathrm{~g} \mathrm{~L}^{-1}$. Biomass of the two studied Streptomyces strains was determined at different growth times by measurement by weighing to constant dry weight after drying at $105^{\circ} \mathrm{C}$.

2.3. Intergeneric Conjugation. Intergeneric conjugation between E. coli and Streptomyces US 24 and TN 58 strains was performed as described previously by Flett et al., [24] with minor modifications. E. coli ET12567 (pUZ8002/pSET152) was grown to an absorbance of $0.4-0.6$ at $600 \mathrm{~nm}$. The cells were pelleted by centrifugation, washed twice in an equal volume of LB, pelleted again, and finally resuspended in $1 / 10$ volume of LB. Aliquots of the two studied Streptomyces strain spores suspension stored at $-20^{\circ} \mathrm{C}$ were used as recipients. Spores $\left(\right.$ eq $\left.10^{8}\right)$ were washed in $2 \times$ yeast extract tryptone medium [25], resuspended in $500 \mu \mathrm{L}$ of $2 \times$ yeast extract tryptone medium, and incubated at $50^{\circ} \mathrm{C}$ for 10 minutes to induce germination. Donor cells $(500 \mu \mathrm{L}$ approximately $10^{8}$ cells) were added to the treated spores, the mixture was pelleted by centrifugation, and finally the pellets were resuspended in the residual liquid, and the undiluted mixtures were plated. The mating mixtures were spread on AS1 plates containing $10 \mathrm{mM} \mathrm{MgCl}_{2}$ and incubated for 18 hours at $37^{\circ} \mathrm{C}$ for the Streptomyces US 24 and at $30^{\circ} \mathrm{C}$ for the Streptomyces TN 58 strain. The plates were overlaid each with $1 \mathrm{~mL}$ of water containing $500 \mu \mathrm{g}$ of nalidixic acid and $1 \mathrm{mg}$ of apramycin, incubated further for 5 days at the appropriate temperature, and the exconjugants were counted. Cultures prepared from some clones were used for further studies. Control experiments were performed as described above but without the addition of $E$. coli donor cells. The viable count of the donor culture was determined by spreading the cells on LB agar plates supplemented with appropriate antibiotics.

2.4. DNA Isolation and Manipulation. Total DNA preparation was carried out from Streptomyces strains according to [21]. Small-scale plasmid preparations from E. coli were performed as described by [20].

Digestion with restriction endonucleases, and separation of DNA fragments by agarose gel electrophoresis, alkaline calf intestinal phosphatase, ligation of DNA fragments, and transformation were done according to [20] for E. coli and [21] for Streptomyces.

For blot manipulations [26], DNA was transferred to Hybond $\mathrm{N}$ nylon membranes (Amersham). About $1 \mu \mathrm{g}$ and $50 \mathrm{ng}$ were loaded for the digested genomic DNA and plasmids DNA, respectively. The hybridization conditions and subsequent detection were in accordance with the manufacturer's instructions. ${ }^{32} \mathrm{P}$-labeled probes were prepared using the Random prime labelling system (Amersham).
PCR amplification of the attB sites of the two studied Streptomyces strains was performed using the two primers ATTB1 and ATTB2 previously described by [10]. Approximately $200 \mathrm{ng}$ genomic template DNA was used with $100 \mathrm{pmol}$ of each primer per $50 \mu \mathrm{L}$ reaction volume. To improve the denaturation of the DNA, 5\% (v/v) DMSO was added to the reaction mixture. Amplifications were performed in a Gene Amp ${ }^{\mathrm{R}}$ PCR System 2700 (Applied Biosystems) using 1U Pfu DNA polymerase (Stratagene) and the recommended buffer system according to the following amplification profile: $94^{\circ} \mathrm{C}$ ( 5 minutes) followed by 45 cycles of denaturation at $94^{\circ} \mathrm{C}$ (30 seconds), annealing at $60^{\circ} \mathrm{C}$ (1 minute) and extension at $72^{\circ} \mathrm{C}$ (1 minute). The PCR reaction mix was analysed by agarose gel electrophoresis, and the products having the expected sizes were purified then cloned into pGEM-T Easy vector.

Nucleotide sequences were determined on both strands using the dideoxy chain-termination method [27]. Reactions were performed with a thermo sequenase cycle sequencing kit (Amersham) and specific primers. Homology search was performed using Blast Search algorithm [28].

2.5. Extraction of Active Compounds and Biological Assay of Antimicrobial Activities. For the extraction of the active molecules from the Streptomyces sp. US 24 and TN 58 strains and their corresponding exconjugants (four exconjugants randomly chosen for each strain), spores at $10^{7} \mathrm{~mL}^{-1}$ were used to inoculate $500 \mathrm{~mL}$ Erlenmeyer flasks with four indents containing $100 \mathrm{~mL}$ of culture medium. After incubation for 24 hours in an orbital incubator with shaking at $250 \mathrm{rpm}$ at the appropriate temperature, the preculture was used to inoculate $(5 \% \mathrm{v} / \mathrm{v})$ a total volume of $1000 \mathrm{~mL}$ culture medium having the same composition of the preculture. After three days incubation at $37^{\circ} \mathrm{C}$ or $30^{\circ} \mathrm{C}$ for Streptomyces US 24 and TN 58 strains, respectively, and their corresponding exconjugants, in an orbital incubator with shaking at $250 \mathrm{rpm}$, the culture broths were filtered to separate mycelium and supernatant. Each supernatant was extracted twice with an equal volume of ethyl acetate and then evaporated on a Rotavapor (Laborata 4000), and obtained crude extract was dissolved in $1 \mathrm{~mL}$ ethyl acetate and used for antibacterial activities as follows: a paper disk was impregnated with $80 \mu \mathrm{L}$ of the corresponding sample and then laid on the surface of an agar plates containing $3 \mathrm{~mL}$ of top agar inseeded by $40 \mu \mathrm{L}$ of a 5 -hour old culture of $M$. luteus LB 14110 or E. coli ATCC 8739. After 2 hours at $4^{\circ} \mathrm{C}$, plates containing $M$. luteus were incubated at $30^{\circ} \mathrm{C}$ and those inoculated with E. coli at $37^{\circ} \mathrm{C}$, all for overnight. Plates were examined for evidence of antibacterial activities represented by a zone of inhibition of growth of the corresponding indicator micro-organisms around the paper disk. Thin layer chromatography (TLC) was performed on silica gel plates $\mathrm{SiO}_{2}$ (Merck). Visualization of active compounds was realised with anisaldehyde vapour and Ehrlich's reagent.

2.6. Expression of the xylA Gene in Streptomyces sp. TN 58. The BglII fragment carrying the insert xylA gene of Streptomyces sp. SK placed under the control of the ermEup constitutive promoter [29] from pMM6 [18] was cloned 
into the Streptomyces integrative vector pSET152 linearised by BamHI, leading to the pSS6 vector construct. This plasmid was firstly obtained within E. coli HB101 strain and then transferred to E. coli ET12567/pUZ8002 for the construction of the Streptomyces TN 58/xylA strains by conjugal transfer. Exconjugants were selected on the basis of apramycin resistance.

Preparation of the cell-free lysate of the Streptomyces SK, TN 58, TN 58/pSET152, TN 58/pSS6, and CBS4 (used as positive control) strains was achieved as follows. The cells were grown in TSB medium for 48 hours and were harvested by centrifugation at $8000 \mathrm{rpm}$ for 10 minutes, and the pellets were suspended in TE-buffer with $10 \mathrm{mM} \mathrm{MgCl}_{2}$ and $1 \mathrm{mM}$ $\mathrm{CoCl}_{2}$. After incubation for an hour on ice in the presence of $5 \mathrm{mgmL}^{-1}$ lysozyme, $100 \mu \mathrm{gmL}^{-1} \mathrm{PMSF}$, and $1 \mu \mathrm{gmL}^{-1}$ Pepstatin A, cells were disrupted by sonication at $4^{\circ} \mathrm{C}$ for 6 minutes (pulsations of 3 seconds, amplify 90) using a vibra cell Sonicator (Fisher-Bioblock Scientific), and debris were removed by centrifugation at $20000 \mathrm{rpm}$ for 30 minutes.

Glucose isomerase activity was determined using fructose as substrate by quantitatively measuring the glucose production. The activity was assayed in a reaction mixture containing the enzyme $(100 \mu \mathrm{L}$ of an appropriate diluted purified or crude extract) with $10 \mathrm{mM} \mathrm{MgCl}, 1 \mathrm{mM} \mathrm{CoCl} 2$ and $15 \%$ fructose, in a volume of $400 \mu \mathrm{L}$. In standard condition, assays were incubated for 30 minutes at $80^{\circ} \mathrm{C}$, and the reaction was stopped by cooling the tubes on ice. The amount of glucose generated was determined by glucoseoxidase (GOD-PAP) enzyme system, and $A_{650}$ was measured after 40 minutes at room temperature. One unit of glucose isomerase activity is defined as the amount of enzyme needed to produce $1 \mu \mathrm{mol}$ of product per minute under the assay conditions. Protein concentration was determined by Bradford's method [30] using the Bovine Serum Albumin as standard.

\section{Results and Discussion}

3.1. Conjugal Transfer of pSET152 and $\varphi$ C31-Directed, SiteSpecific Recombination in Streptomyces sp. US 24 and Streptomyces sp. TN 58 Strains. The plasmid pSET152 was mobilized from E. coli ET12567 (pUZ8002) into Streptomyces sp. US 24 and TN 58 strains. Exconjugants were obtained at a frequency of approximately $5 \times 10^{-5}$ and $3 \times 10^{-4}$ per recipient spore of Streptomyces sp. US 24 and TN 58 strains, respectively, which showed a high frequency of exconjugants. Indeed, Nikodinovic et al., [31] consider that the transformation efficiency $\left(5 \times 10^{-5}\right.$ exconjugants recipient $^{-1}$ ) of the Streptomyces nodosus by conjugal transfer of DNA from E. coli was a high transformation frequency.

The integrative plasmid pSET152 cannot replicate in Streptomyces; so stable exconjugants should be obtained only if pSET152 has been integrated into the chromosome of studied strain. In order to identify the copy number of pSET152 in the recipient Streptomyces sp. US24 and Streptomyces sp. TN 58, eight arbitrary chosen exconjugants were studied for each strain. Chromosomal DNAs were extracted, digested by BamHI and probed with the whole linearised vector pSET152 in a blot analysis. Since pSET152 had a single BamHI site, DNA from exconjugants was expected to show hybridisation of two fragments to probe in the case of single copy integration.

For Streptomyces sp. US24 exconjugants, obtained hybridisation patterns were identical and showed the presence of three bands of about $5.7,6.2$, and $7.8 \mathrm{~Kb}$ (Figure 1(a)). The same probe did not hybridise to any DNA fragment of the wild type genomic DNA. This result implied that the plasmid was presumably integrated at the same locus in all corresponding exconjugants. However, among the three obtained bands, the one of $5.7 \mathrm{~kb}$ corresponds exactly to the size of the linearized vector pSET152. This fact can be explained via the tandem integration of two copies of the pSET152 vector in the chromosome of Streptomyces sp. US24 strain (Figure 1(b)). The presence of tandemly repeated copies of pSET152 vector in the attB site can be explained by the property of pSET152 to integrate at attR or att $L$ sites via attP/attR or attP/att L recombination. Normally, the integration of pSET152 vector will be via attB/attP recombination. So, in certain cases, we can assist to the multiple independent recombination events, and pSET152 can integrate at attL or attR sites via attP/attL or attP/attR. As was hypothesised by Combes et al. [10], if this event occurs, this reaction must be specific to the att $L$ and attR sites as tandem repeats of pSET152 in the pseudo-attB sites were not generally observed. Alternatively, the generation of tandem repeats of pSET152 in the attB may be a consequence of the rate of integration. If the rate of recombination into the attB site is rapid, integration occurs early during the mating period, and when the hyphae containing integrated pSET152 receives a further copy of pSET152, this last one may, generally, integrate by homologous recombination to generate a tandem repeat.

Concerning Streptomyces TN 58, two identical hybridisation signals were obtained for all eight analysed exconjugants corresponding to two DNA fragments of about 6.8 and $8 \mathrm{~Kb}$ (Figure 2(a)). The same probe did not hybridise to any DNA fragment of untransformed Streptomyces. sp TN 58 genomic DNA. This result implied that a single copy of the pSET152 plasmid was integrated at the same locus in all the exconjugants in strain Streptomyces sp. TN 58. We can suggest that the chromosome of this strain contains a single functional attBsite for vectors that integrate site specifically using the bacteriophage $\varphi \mathrm{C} 31$ att/int system (Figure 2(b)). All together, our data strongly suggest the presence of an efficiently recognised $a t t B$ site in the chromosome of the two studied Streptomyces strains.

3.2. Identification of the $\Phi C 31$ attB Sites. Integration of pSET152 into the Streptomyces sp. US 24 and TN 58 strains chromosomes implies the existence of one attB site recognised by the $\Phi C 31$ integrase. Taking advantage of the two PCR primers (ATTB1 and ATTB2) described by Combes et al., [10], we recovered a unique PCR product at the expected size of approximately $0.3 \mathrm{~Kb}$ from the chromosomal DNAs of the two studied strains. These fragments were cloned into the pGEM-T Easy vector yielding pSS4 and pSS5 plasmids for US 24 and TN 58 strains, respectively. The insert of three randomly chosen clones for pSS4 and 




(a)

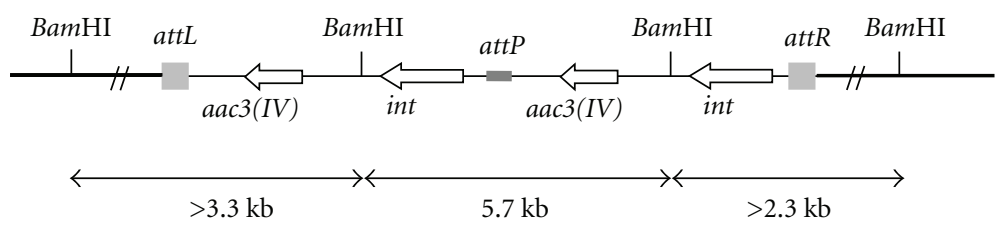

(b)

FIgURe 1: (a) Southern blot of Streptomyces sp. US24 BamHI-digested total DNA hybridised with ${ }^{32}$ P-labeled pSET152 plasmid. Lane 1, untransformed wild type Streptomyces sp. US24; lanes 2-9, the eight studied exconjugants; lane 10, BamHI-digested pSET152 plasmid DNA (5.7 Kb); lane 11, the $1 \mathrm{~kb}$ ladder used as DNA marker. (b) Schematic representation of tandemly insertion of the pSET152 into the Streptomyces sp. US24 attB site. Chromosomal DNA hybridising is represented by thin lines and pSET152 by thick line. The integrase gene (int), and the apramycin resistance gene $[a a c 3(I V)]$ from pSET152 attP, attL, and attR sites are also shown.

pSS5 plasmids was sequenced. All three nucleotide sequences were identical for each plasmid insert. The two inserts possess a size of $292 \mathrm{bp}$ and $293 \mathrm{bp}$ for US 24 and TN 58 strains, respectively, and a high nucleotide identity of $86 \%$ (Figure 3). These two amplified DNA fragments encode a homolog of the Streptomyces coelicolor A3(2) Sco3798 ORF with a nucleotide identity of $92 \%$ and $86 \%$ for Streptomyces sp. US 24 and Streptomyces TN 58 strains, respectively. This ORF is a putative chromosome condensation protein, with sequence similarity to a mammalian-encoded protein, pirin (an identified nuclear protein that interacts with Bcl-3 and nuclear factor I), in which the $a t t B$ site of $\Phi C 31$ lies in various Streptomyces species [32].

For Streptomyces species, all characterised ФC31 attB sites showed high nucleotide sequence similarity varying from $82.4 \%$ to $100 \%$. However, the presence of pseudo-attB sites $(50 \%--70.3 \%$ nt identity to attB sites) into which integration occurred at a frequency 300 times lower than into the corresponding attB site [10] has also been reported in this genus of bacteria. The multiple-sequence alignment of attB sites of Streptomyces sp. US 24 and TN 58 with several other Streptomycesspecies is shown in Figure 4. This alignment indicates that these sequences are conserved, and some positions in the minimal site can tolerate nucleotide changes. Kuhstoss and Rao [33] reported, by comparing the $S$. ambofaciens attB site with attP, that the core sequence (i.e., the region at which the crossover occurs) is $5^{\prime}$ TTG. Combes et al., [10] had shortened this sequence to two nucleotides 5'TT which was present in the attB site of both studied strains Streptomyces sp. US 24 and TN 58.

\subsection{Site-Specific Integration Does Not Affect the Essential} Functions and Active Molecule Production of Streptomyces sp. US 24 and Streptomyces sp. TN 58 Strains. Despite their wide use and clear advantages, it has been reported that integration of the integrative vectors into the $\varphi \mathrm{C} 31$ attB site can cause detrimental effects on antibiotic production in some strains [34]. In fact, it should be considered that the decrease in antibiotics production for many Streptomyces strains carrying integrated site specific plasmids such as $S$. fradiae producer of tylosin, S. kanamyceticus producer of kanamycin and others has been reported [35]. Therefore, while integrative vectors could be used for the development of stable recombinant producers of antibiotics, their possible negative effect on the level of antibiotic production should be considered. Thus, in order to determine whether the site-specific integration of the plasmid pSET152 affected relevant functions of Streptomyces sp. US 24 and Streptomyces sp. TN 58 strains, we have followed the growth of both strain and their corresponding exconjugants carrying plasmid pSET152. All exconjugants grew well in the minimal 




(a)

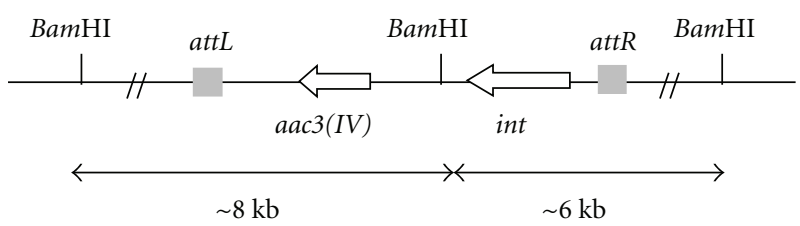

(b)

Figure 2: (a) Southern blot of Streptomyces sp. TN 58 BamHI-digested total DNA hybridised with ${ }^{32}$ P-labeled pSET152 plasmid. Lanes 1-8, the eight studied exconjugants; lane 9, untransformed wild type Streptomyces sp. TN 58; lane 10, BamHI-digested pSET152 plasmid DNA (5.7 Kb); lane 11, the $1 \mathrm{~kb}$ ladder used as DNA marker. (b) Schematic representation of the integration of plasmid pSET152 in the chromosome of Streptomyces sp. TN 58 by site-specific recombination.

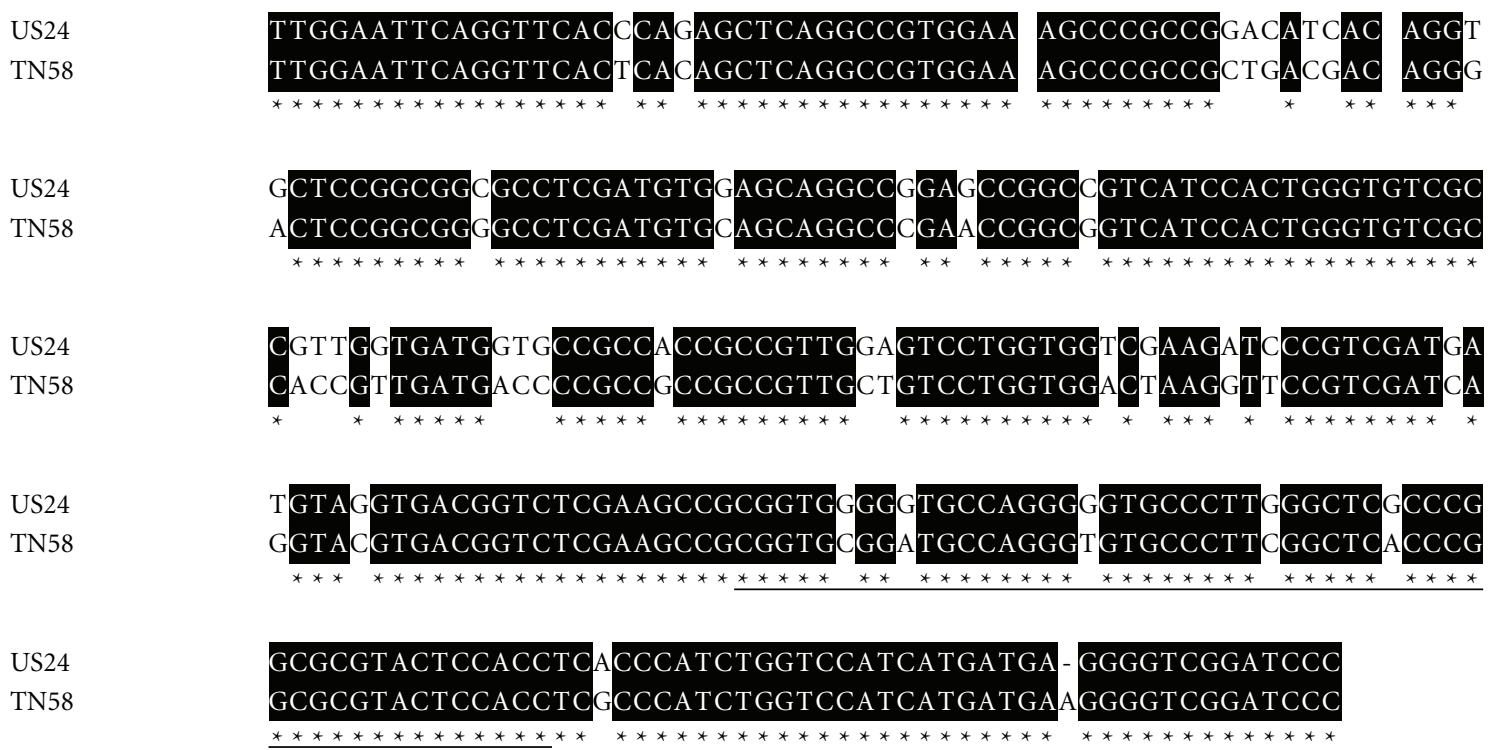

FIgURE 3: Alignment of the attB region of Streptomyces sp. US 24 and TN 58 strains. Solid boxes, identical sequences, underlined sequence, attB site. 


S. US 24
S. TN 58
S. hygro
S. averm
S. longi
S. coeli
S. clavu
S. cinna
S. aureo
S. livid
S. grise
S. ambof
consensus

$a t t P$

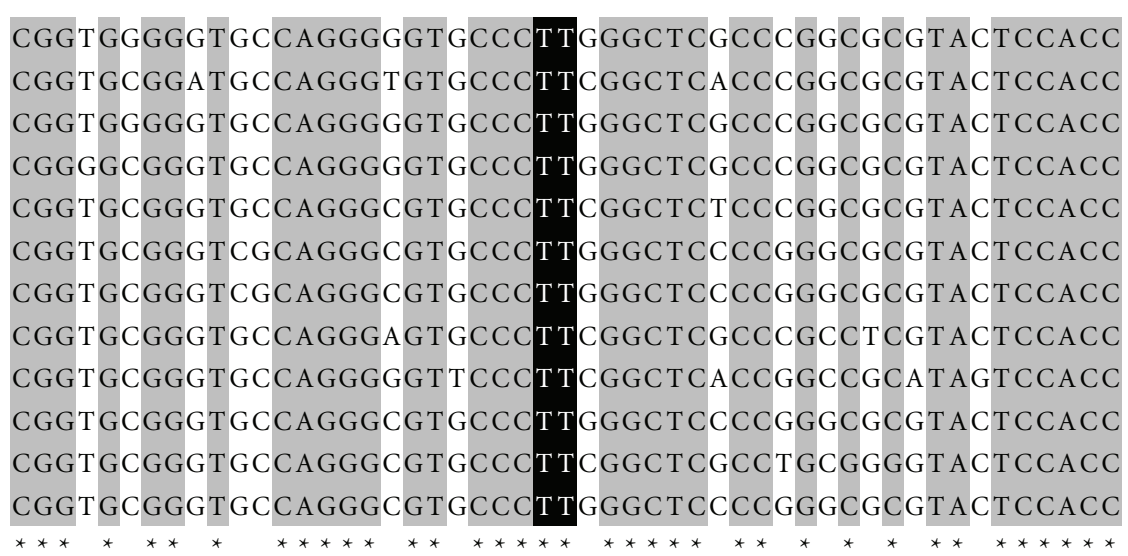

(a)

GT AGT GCCCCAACTGGGGT AACCT T TGAGT TC T C TCAGT TGGGGGCGT AGG

(b)

FIGURE 4: Natural variation of $Ф C 31$ attB sites in various species of Streptomyces. (a) Alignment of attB nucleotide sequence of Streptomyces sp. US 24 strain (S. US 24) and Streptomyces sp. TN 58 (S. TN 58) with attB sequences of S. hygroscopicus NRRL5491 (S. hygro); S. avermitilis MA-4680 (S. aver); S. longisporoflavus 83E6 (S. longi); S. coelicolor (S. coel); S. clavugerus (S. clav); S. cinnamonensis (S. cinna); S. aureofaciens (S. aureo); S. lividans 66 TK64 (S. livid); S. griseus ATCC 12475 (S. grise); S. ambofaciens (S. ambof). Dark boxes, identical sequences; black shading sequence at which crossover occurs (TT) for the natural attB and attP sites. (b); Sequence of the attP site in $\varphi \mathrm{C} 31$.

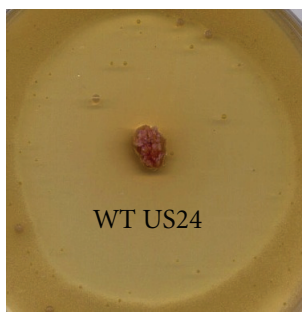

(a1)

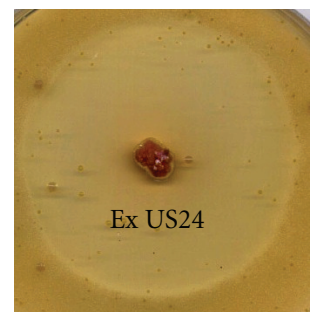

(a2)

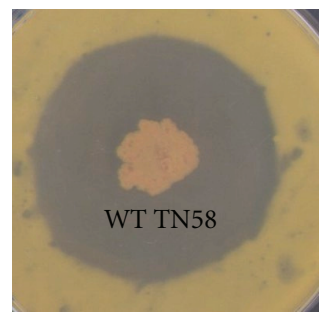

(b1)

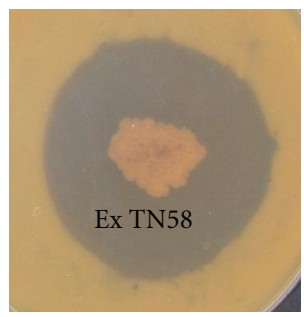

(b2)

Figure 5: Antibacterial activities in solid media against M. luteus of the Streptomyces sp. US 24 strain wild type "WT US24" (a1) and one corresponding exconjugant US24/pSET152 "Ex US24" (a2) and Streptomyces TN 58 strain wild type "WT TN 58" (b1) and one corresponding exconjugant TN 58/pSET152 “Ex TN 58” (b2).

medium, and there was no difference compared to the wild type strains. The presence of pSET152 had no effects on growth and sporulation of the two strains. We have studied the stability of the pSET152 inheritance in exconjugants. This stability was determined as the proportion of colonies that retained resistance to apramycin (at $50 \mu \mathrm{g} \mathrm{mL}^{-1}$ ) after several passages of the exconjugants under nonselective conditions. Plasmid pSET152 was inherited every time for the all studied exconjugants under nonselective conditions for both strains. Meanwhile, antimicrobial activity was determined by observing bacterial growth inhibition of the wild type strains (US 24 and TN 58) and corresponding exconjugants. There was no obvious difference between wild type Streptomyces sp. US 24 and Streptomyces sp. TN 58 and their corresponding exconjugants (Figure 5 and Table 1). In addition, the analysis on TLC plates of the ten studied active crude extracts revealed the presence of the expected active molecules in each strain and its corresponding exconjugants. For the Streptomyces sp. US 24 strain and its four studied exconjugants, two bands were easily detected on TLC plates under UV light at $254 \mathrm{~nm}$ after spraying with anisaldehyde/sulphuric acid. The first band gives an orange colouration with a retention factor, $\mathrm{Rf}=0.46\left(\mathrm{CHCl}_{3} / \mathrm{MeOH} 10 \%\right)$ and the second one a violet colouration, Rf $=0.37\left(\mathrm{CH}_{2} \mathrm{Cl}_{2} / 9 \% \mathrm{MeOH}\right)$. According to our previously work [14], these two bands correspond to the 3-indolethanol and the Cyclo (L-Phe, L-Pro) diketopiperazine active molecules, respectively. Concerning the Streptomyces sp. TN 58 strain and its studied exconjugants, the five active molecules (M1 to M5) were present in all five crude extracts. M1 belongs to the acetyltryptamine family and gives a colouration orange and violet after anisaldehyde/sulphuric acid and Erhlich's reagent visualisation. The $\mathrm{Rf}$ of this molecule is $0.5\left(\mathrm{CHCl}_{3} / 5 \% \mathrm{MeOH}\right)$. $\mathrm{M} 2, \mathrm{Rf}=0.57\left(\mathrm{CH}_{2} \mathrm{Cl}_{2} / 1 \% \mathrm{MeOH}\right)$, and $\mathrm{M} 3, \mathrm{Rf}=0.47$, $\left(\mathrm{CHCl}_{3} / 5 \% \mathrm{MeOH}\right)$ belong to the thiazole and brevinamide families, respectively. M2 gives a chestnut colouration on spraying with anisaldehyde/sulphuric acid and M3 gives a pinkish colouration after Erhlich's reagent visualisation. 
TABle 1: Antibacterial activities in liquid media against M. luteus and E. coli of the two studied Streptomyces strains and their corresponding exconjugants. WT (wild type). Ex (Exconjugant).

\begin{tabular}{|c|c|c|c|c|c|c|c|c|c|c|}
\hline \multirow[b]{3}{*}{ Indicator microorganisms } & \multicolumn{10}{|c|}{ Diameter $(\mathrm{mm})$ of inhibition zones } \\
\hline & \multicolumn{5}{|c|}{ Streptomyces sp. US24 } & \multicolumn{5}{|c|}{ Streptomyces TN 58} \\
\hline & WT & Ex. $24^{1}$ & Ex. $24^{2}$ & Ex. $24^{3}$ & Ex. $24^{4}$ & WT & Ex. $58^{1}$ & Ex. $58^{2}$ & Ex. $58^{3}$ & Ex. $58^{4}$ \\
\hline M. luteus & 20 & 19 & 20 & 21 & 20 & 17 & 17 & 16 & 17 & 17 \\
\hline E. coli & 21 & 21 & 20 & 21 & 21 & 15 & 15 & 15 & 16 & 16 \\
\hline
\end{tabular}

TABle 2: Glucose isomerase activity of Streptomyces TN 58 wild type (S. TN 58), Streptomyces TN 58/pSET152 (S. TN 58/pSET152), Streptomyces sp. SK (S. SK), CBS4, and Streptomyces TN 58/xylA (S. TN 58/xylA ) strains from 48-hour old cultures.

\begin{tabular}{lccccc}
\hline & S. TN 58 & S. TN 58/pSET152 & S. SK & CBS4 & S. TN 58/xylA \\
\hline Specific activity $\mathrm{U} \mathrm{mg}^{-1}$ & 0 & 0 & 0.1 & 1.68 & 1.81 \\
\hline
\end{tabular}

The two other active molecules (M4 and M5) characterised from the Streptomyces sp. TN 58 strain, and belonging to the rhamnopyranosides family, do not have antimicrobial activities, but they possess inhibitory activity towards $3 \alpha$ hydroxysteroid dehydrogenase ( $3 \alpha-\mathrm{HSD})$. Indeed, the rhamnosylated aromatic compounds were easily detected on TLC plates due to their striking yellow/greenish colouration after visualisation with anisaldehyde vapour. For all five analysed crude extracts, the wild type one (from the Streptomyces sp. TN 58 strain) and those from the four corresponding exconjugants, we obtained similar TLC migration profiles and two yellow/greenish bands having a retention factor $\left(\mathrm{CHCl}_{3} / 15 \% \mathrm{MeOH}\right)$ of 0.22 and 0.33 corresponding to the two molecules belonging to the rhamnopyranoside family. For the five active molecules of the Streptomyces sp. TN 58 and its four studied exconjugants, TLC profiles, bands colouration, and retention factors of the different active compounds were in perfect concordance with the results of previously works [15]. These data clearly demonstrated that the morphological differentiation and active molecule production of all studied pSET152 integrated exconjugants were similar to those of wild type Streptomyces sp. US 24 and Streptomyces sp. TN 58 strains. Consequently, conjugal transfer using $a t t P / B$ site integration can be concluded to be a suitable means of gene transfer and expression for both studied strains.

3.4. Heterologous Expression of xylA Gene in Streptomyces sp. TN 58 Strain. The establishment of a gene transfer system and the stable integration of cloned genes at the specific loci in the genome of Streptomyces sp. TN 58 prompted us to express some heterologous gene in this strain. Xylose isomerase (D-xylose ketol isomerase EC 5.3.1.5) catalyses the reversible isomerisation of D-xylose into D-xylulose. It is also referred to as glucose isomerase (GI) because of its ability to convert $\mathrm{D}$-glucose to $\mathrm{d}$-fructose. This property is widely exploited industrially for the production of high-fructose syrup from starch [36]. Thus, the enhancement of strain productivity is certainly of importance. So we expressed the $x y l A$ gene cloned from Streptomyces. sp SK [17], and we attempted to examine whether this gene could express and fold effectively in strain TN 58. It should be noted that the wild type Streptomyces TN 58 strain cannot assimilate the xylose as solely carbon source. Heterologous xylA gene was inserted into pSET152 to yield pSS6 plasmid. Based on intergeneric conjugal transfer, transformation efficiency of strain TN 58 by plasmid pSS6 was achieved at high frequency $\left(10^{-4}\right.$ exconjugants recipient ${ }^{-1}$ ). The chromosomal structure of three TN 58/xylA strains, arbitrary chosen, was checked by Southern Blot hybridisation using the $800 \mathrm{bp}$ Pst I DNA fragment internal to PSET152 as probe, which contain the oriT region. As expected, a unique and identical large $\mathrm{BamHI}$ band was obtained for the three TN 58/xylA strains chromosomal DNA, whereas wild type strain TN 58 chromosomal DNA does not hybridise to the probe (data not shown). One of the three recombinant strains studied was subcloned five times on a solid media in the absence of apramycin followed by cultivation for several generations in liquid media in the absence of selection pressure. The plating of this culture on solid media, on both with and without selective pressures, showed that $100 \%$ of the colonies were apramycin resistant and able to grow in the presence of xylose as solely carbon source.

Determination of the mycelial intracellular glucose isomerase activity of Streptomyces TN 58, Streptomyces TN 58/pSET152, Streptomyces sp. SK, CBS4, and TN 58/xylA strains shows that glucose isomerase activity of the TN 58/xylA recombinant strain is of about eighteenfold higher than that of the SK strain and comparable to that of CBS4 strain. No activity was detected for the wild type TN 58 strain and the recombinant strain TN 58/pSET152 (Table 2). Study of the growth of the two strains, Streptomyces TN 58/xylA and CBS4, in minimum liquid media containing xylose as solely carbon source showed that the two strains grew well, and for each time, the resulting biomass was quite similar. It should be noted that glucose isomerase activity is correlated with biomass production, and optimum activity has been obtained after 48 hours of incubation.

According to these results, we can deduce that sitespecific recombination directed by pSET152 makes it possible to stably insert heterologous DNA in strain TN 58. This should be very important for a number of cases such as genes expression, genetic complementation, and biosynthetic pathway manipulations of the active molecules of this strain especially those belonging to the rhamnopyranoside family. 


\section{Acknowledgments}

This work was supported by the Tunisian government (Contract Program CBS-LEMP) and the CMCU project (2006-2008) no. 06/S 0901 "MELLOULI/AIGLE".

\section{References}

[1] P. Mazodier, R. Petter, and C. Thompson, "Intergeneric conjugation between Escherichia coli and Streptomyces species," Journal of Bacteriology, vol. 171, no. 6, pp. 3583-3585, 1989.

[2] M. Bierman, R. Logan, K. O’Brien, E. T. Seno, R. N. Rao, and B. E. Schoner, "Plasmid cloning vectors for the conjugal transfer of DNA from Escherichia coli to Streptomyces spp," Gene, vol. 116, no. 1, pp. 43-49, 1992.

[3] P. Matsushima and R. H. Baltz, "A gene cloning system for 'Streptomyces toyocaensis," Microbiology, vol. 142, no. 2, pp. 261-267, 1996.

[4] R. Fouces, M. Rodríguez, E. Mellado, B. Díez, and J. L. Barredo, "Conjugation and transformation of Streptomyces species by tylosin resistance," FEMS Microbiology Letters, vol. 186, no. 2, pp. 319-325, 2000.

[5] D. J. MacNeil, J. L. Occi, K. M. Gewain, et al., "Complex organization of the Streptomyces avermitilis genes encoding the avermectin polyketide synthase," Gene, vol. 115, no. 1-2, pp. 119-125, 1992.

[6] E. Stegmann, S. Pelzer, K. Wilken, and W. Wohlleben, "Development of three different gene cloning systems for genetic investigation of the new species Amycolatopsis japonicum MG417-CF17, the ethylenediaminedisuccinic acid producer," Journal of Biotechnology, vol. 92, no. 2, pp. 195-204, 2001.

[7] T. Voeykova, L. Emelyanova, V. Tabakov, and N. Mkrtumyan, "Transfer of plasmid pTO1 from Escherichia coli to various representatives of the order Actinomycetales by intergeneric conjugation," FEMS Microbiology Letters, vol. 162, no. 1, pp. 47-52, 1998.

[8] R. Fouces, M. Rodríguez, E. Mellado, B. Díez, and J. L. Barredo, "Conjugation and transformation of Streptomyces species by tylosin resistance," FEMS Microbiology Letters, vol. 186, no. 2, pp. 319-325, 2000.

[9] A. C. Groth, E. C. Olivares, B. Thyagarajan, and M. P. Calos, "A phage integrase directs efficient site-specific integration in human cells," Proceedings of the National Academy of Sciences of the United States of America, vol. 97, no. 11, pp. 5995-6000, 2000.

[10] P. Combes, R. Till, S. Bee, and M. C. M. Smith, "The Streptomyces genome contains multiple pseudo-attB sites for the $\phi \mathrm{C} 31$-encoded site-specific recombination system," Journal of Bacteriology, vol. 184, no. 20, pp. 5746-5752, 2002.

[11] M. A. Gregory, R. Till, and M. C. M. Smith, "Integration site for Streptomyces phage $\phi \mathrm{BT} 1$ and development of site-specific integrating vectors," Journal of Bacteriology, vol. 185, no. 17, pp. 5320-5323, 2003.

[12] L. Mellouli, R. Ben Ameur-Mehdi, S. Sioud, M. Salem, and S. Bejar, "Isolation, purification and partial characterization of antibacterial activities produced by a newly isolated Streptomyces sp. US24 strain," Research in Microbiology, vol. 154, no. 5, pp. 345-352, 2003.

[13] L. Mellouli, I. Karray-Rebai, S. Sioud, R. Ben Ameur-Mehdi, B. Naili, and S. Bejar, "Efficient transformation procedure of a newly isolated Streptomyces sp. TN58 strain producing antibacterial activities," Current Microbiology, vol. 49, no. 6, pp. 400-406, 2004.
[14] R. Ben Ameur-Mehdi, L. Mellouli, F. Chabchoub, S. Fotso, and S. Bejar, "Purification and structure elucidation of two biologically active molecules from a new isolated Streptomyces sp. US 24 strain," Chemistry of Natural Compounds, vol. 40, no. 5, pp. 510-513, 2004.

[15] R. Ben Ameur-Mehdi, K. A. Shaaban, I. Karray-Rebai, S. Smaoui, S. Bejar, and L. Mellouli, "Five naturally bioactive molecules including two rhamnopyranoside derivatives isolated from the Streptomyces sp. strain TN58," Natural Product Research. In press.

[16] D. Hanahan, "Studies on transformation of Escherichia coli with plasmids," Journal of Molecular Biology, vol. 166, no. 4, pp. 557-580, 1983.

[17] K. Srih-Belghith and S. Bejar, "A thermostable glucose isomerase having a relatively low optimum $\mathrm{pH}$ : study of activity and molecular cloning of the corresponding gene," Biotechnology Letters, vol. 20, no. 6, pp. 553-556, 1998.

[18] M. Mezghani, M. A. Borgi, R. Kammoun, H. Aouissaoui, and S. Bejar, "Construction of new stable strain over-expressing the glucose isomerase of the Streptomyces sp. SK strain," Enzyme and Microbial Technology, vol. 37, no. 7, pp. 735-738, 2005.

[19] M. S. B. Paget, L. Chamberlin, A. Atrih, S. J. Foster, and M. J. Buttner, "Evidence that the extracytoplasmic function sigma factor $\sigma^{\mathrm{E}}$ is required for normal cell wall structure in Streptomyces coelicolor A3(2)," Journal of Bacteriology, vol. 181, no. 1, pp. 204-211, 1999.

[20] J. Sambrook, E. F. Fritsch, and T. Maniatis, Molecular Cloning: A Laboratory Manual, Cold Spring Harbor Laboratory Press, Cold Spring Harbor, NY, USA, 2nd edition, 1989.

[21] D. A. Hopwood, M. J. Bibb, K. F. Chater, et al., Genetic Manipulation of Streptomyces: A Laboratory Manual, The John Innes Foundation, Norwich, UK, 1985.

[22] C. J. Thompson, J. M. Ward, and D. A. Hopwood, "DNA cloning in Streptomyces: resistance genes from antibioticproducing species," Nature, vol. 286, no. 5772, pp. 525-527, 1980.

[23] R. H. Baltz, "Genetic recombination by protoplast fusion in Streptomyces," Developments in Industrial Microbiology, vol. 21, pp. 43-54, 1980.

[24] F. Flett, V. Mersinias, and C. P. Smith, "High efficiency intergeneric conjugal transfer of plasmid DNA from Escherichia coli to methyl DNA-restricting streptomycetes," FEMS Microbiology Letters, vol. 155, no. 2, pp. 223-229, 1997.

[25] T. Kieser, M. J. Bibb, M. J. Bittner, K. F. Chater, and D. A. Hopwood, Practical Streptomyces Genetics: A Laboratory Manual, The John Innes Foundation, Norwich, UK, 2000.

[26] T. E. Maniatis, E. F. Fritsch, and J. Sambrook, Molecular Cloning: A Laboratory Manual, Cold Spring Harbor Laboratory, Cold Spring Harbor, NY, USA, 1982.

[27] F. Sanger, S. Nicklen, and A. R. Coulson, "DNA sequencing with chain-terminating inhibitors," Proceedings of the National Academy of Sciences of the United States of America, vol. 74, no. 12 , pp. 5463-5467, 1977.

[28] S. F. Altschul, T. L. Madden, A. A. Schäffer, et al., "Gapped BLAST and PSI-BLAST: a new generation of protein database search programs," Nucleic Acids Research, vol. 25, no. 17, pp. 3389-3402, 1997.

[29] M. J. Bibb, G. R. Janssen, and J. M. Ward, "Cloning and analysis of the promoter region of the erythromycin resistance gene (ermE) of Streptomyces erythraeus," Gene, vol. 38, no. 1-3, pp. 215-226, 1985.

[30] M. M. Bradford, "A rapid and sensitive method for the quantitation of microgram quantities of protein utilizing the 
principle of protein dye binding," Analytical Biochemistry, vol. 72, no. 1-2, pp. 248-254, 1976.

[31] J. Nikodinovic, K. D. Barrow, and J.-A. Chuck, "High frequency transformation of the Amphotericin-producing bacterium Streptomyces nodosus," Journal of Microbiological Methods, vol. 55, no. 1, pp. 273-277, 2003.

[32] S.-U. Choi, C.-K. Lee, Y.-I. Hwang, H. Kinoshita, and T. Nihira, "Intergeneric conjugal transfer of plasmid DNA from Escherichia coli to Kitasatospora setae, a bafilomycin $\mathrm{B}_{1}$ producer," Archives of Microbiology, vol. 181, no. 4, pp. 294 298, 2004.

[33] S. Kuhstoss and R. N. Rao, "Analysis of the integration function of the streptomycete bacteriophage $\varphi$ C31," Journal of Molecular Biology, vol. 222, no. 4, pp. 897-908, 1991.

[34] R. H. Baltz, "Genetic manipulation of antibiotic-producing Streptomyces," Trends in Microbiology, vol. 6, no. 2, pp. 76-83, 1998.

[35] A. N. Luzhetskii, B. E. Ostash, and V. A. Fedorenko, "Intergeneric conjugation Escherichia coli-Streptomyces globisporus 1912 using integrative plasmid pSET152 and its derivatives," Russian Journal of Genetics, vol. 37, no. 10, pp. 1123-1129, 2001.

[36] S. H. Bhosale, M. B. Rao, and V. V. Deshpande, "Molecular and industrial aspects of glucose isomerase," Microbiological Reviews, vol. 60, no. 2, pp. 280-300, 1996. 

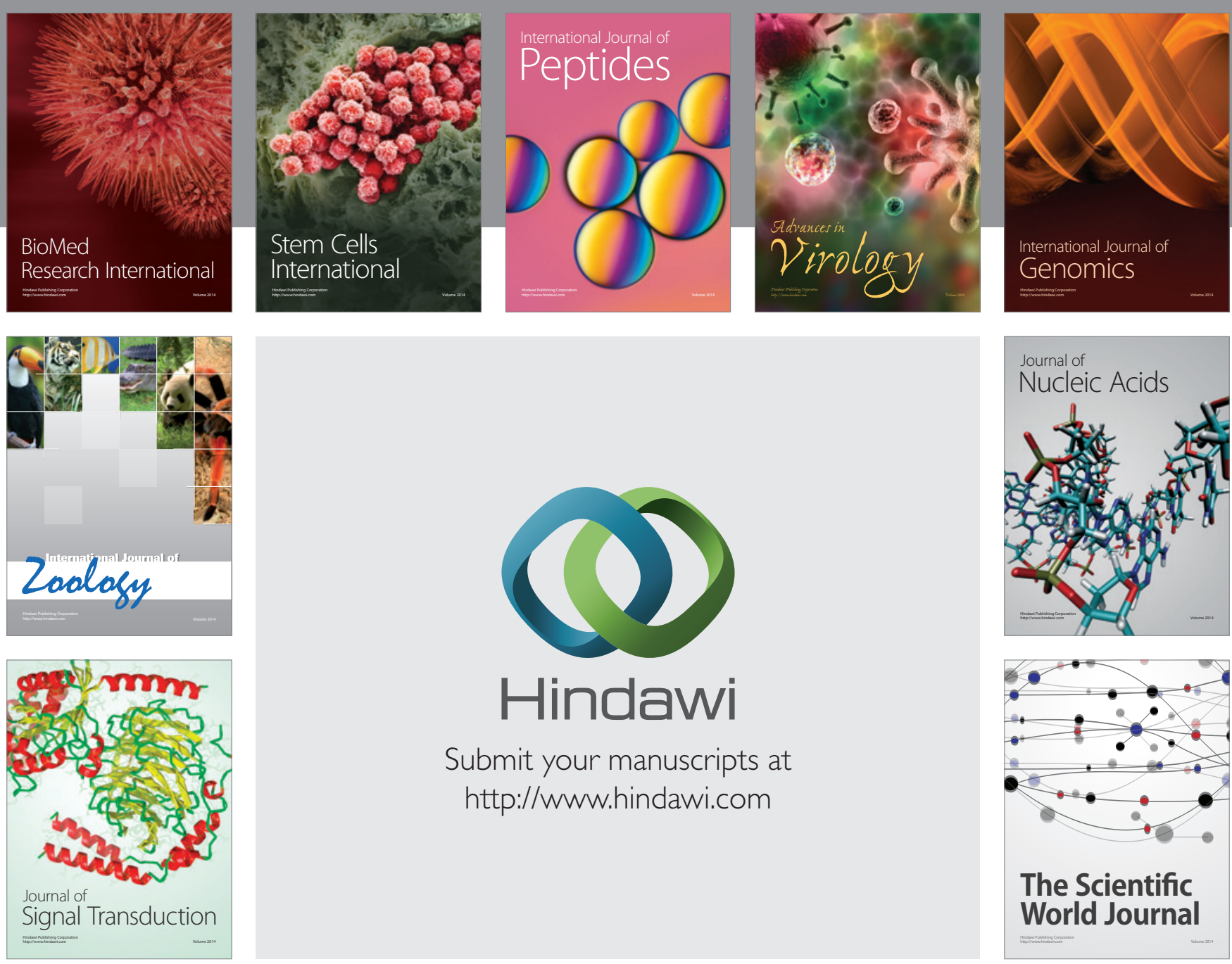

Submit your manuscripts at

http://www.hindawi.com
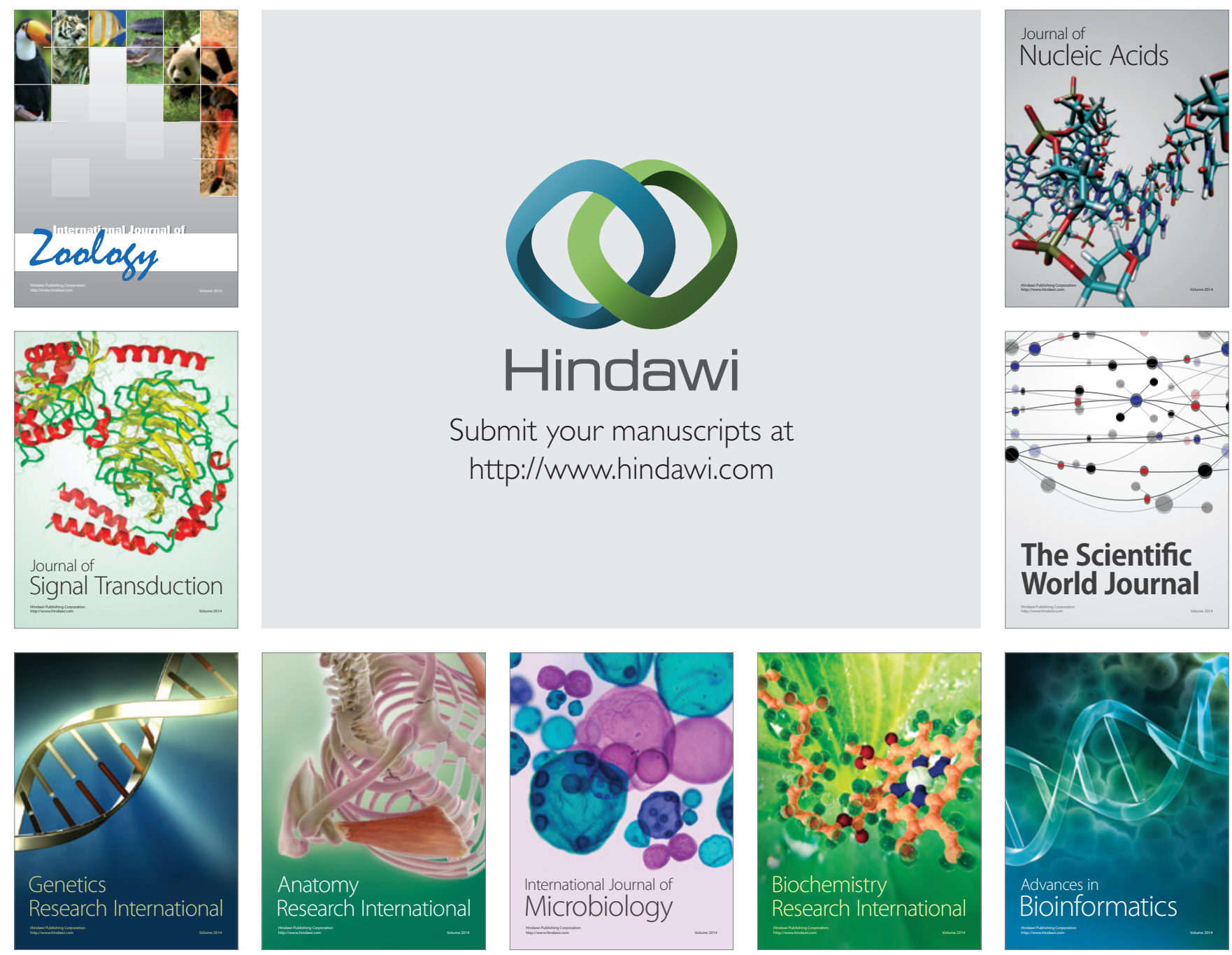

The Scientific World Journal
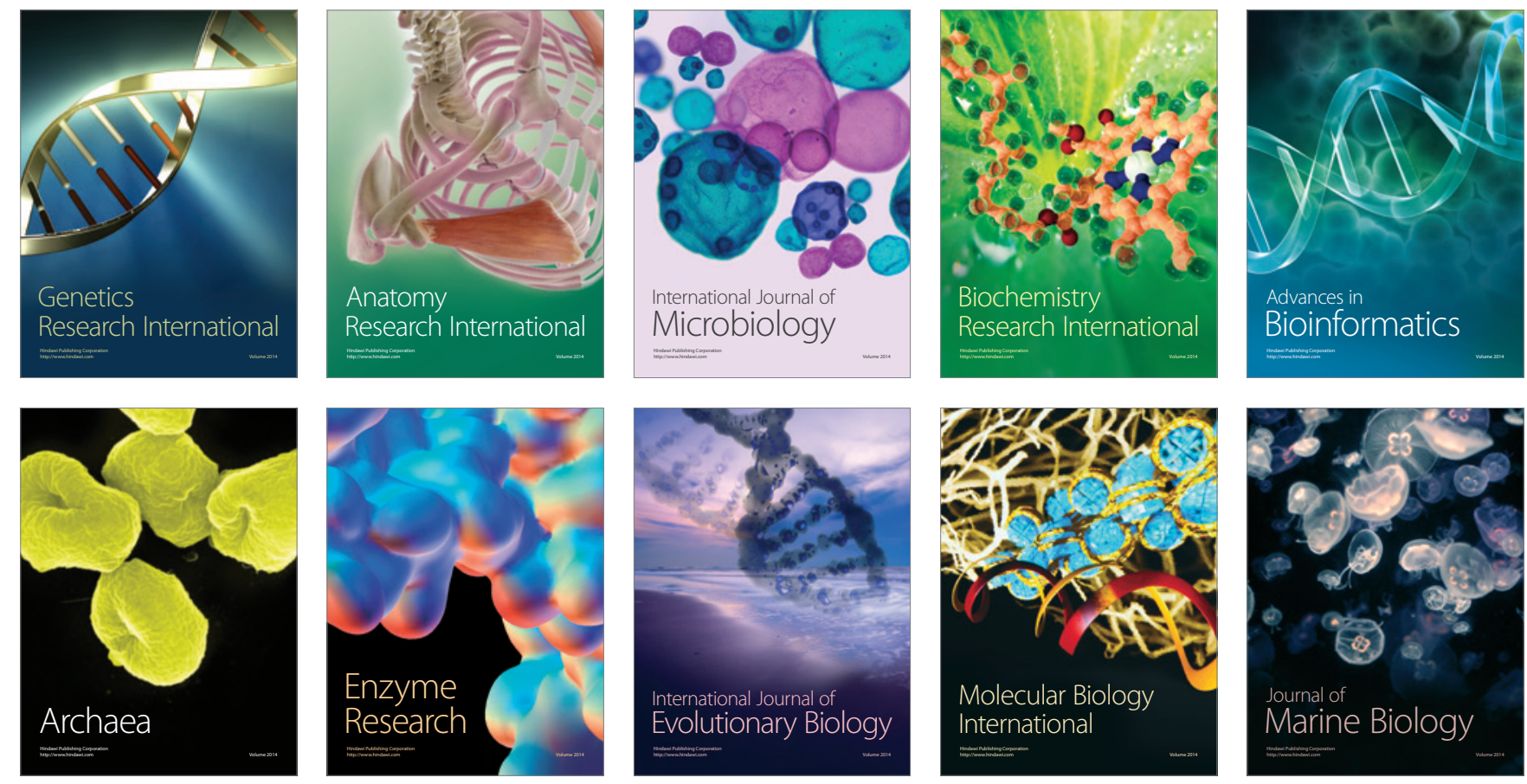